\title{
Foraging selectivity by larval yellow perch (Perca flavescens): implications for understanding recruitment in small and large lakes
}

\author{
Richard S. Fulford, James A. Rice, Thomas J. Miller, Fred P. Binkowski, \\ John M. Dettmers, and Brian Belonger
}

\begin{abstract}
Growth and survivorship of larval yellow perch (Perca flavescens) have been examined in many systems but can conclusions from well-studied perch populations in smaller lakes be applied to populations in meso-oceanic systems like Lake Michigan, USA? Laboratory experiments were conducted with yellow perch (hatch to $35 \mathrm{~mm}$ total length) to develop an empirical selectivity function based on Chesson's $\alpha$ to describe larval diet as a function of changes in prey community composition. This function was used in an individual-based foraging and growth model (IBM) to describe changes in foraging decisions resulting from changes in prey composition between different systems. Larval perch made three selective transitions during ontogeny. Initial positive selection for rotifers and the relative selectivity for cladocerans vs. copepods in late-stage larvae were both dependent on prey composition. Larvae exposed to prey assemblages differing only in composition had different diets. The empirically based IBM accurately predicted these dietary differences and resulting differences in larval growth and likelihood of starvation between systems at equal prey density. The importance of feeding behavior to larval survival will differ between Lake Michigan and smaller lakes, and these results are important for comparisons of recruitment dynamics between large and small systems.
\end{abstract}

Résumé : La croissance et la survie des larves de la perchaude (Perca flavescens) ont été étudiées dans plusieurs systèmes, mais il reste à savoir si les conclusions tirées de populations bien analysées dans les lacs plus petits sont applicables aux populations de systèmes méso-océaniques, tels que le lac Michigan, É.-U. Nous avons mené des expériences de laboratoire avec des perchaudes (de l'éclosion à $35 \mathrm{~mm}$ de longueur totale) afin de mettre au point une fonction de sélectivité empirique basée sur l' $\alpha$ de Chesson pour décrire le régime alimentaire des larves en fonction des changements dans la communauté de proies. Cette fonction sert dans un modèle de la recherche de nourriture et de la croissance basé sur l'individu (IBM) à décrire les changements dans les décisions de recherche de nourriture résultant de variations de la composition des proies dans les divers systèmes. Les larves de perchaude traversent trois périodes de transition dans leur sélection alimentaire durant leur ontogénie. Une sélection initiale positive pour les rotifères et une sélection relative pour les cladocères par rapport aux copépodes chez les larves avancées sont toutes deux reliées à la composition des proies. Les larves exposées à des ensembles de proies qui diffèrent seulement par leur composition ont des régimes alimentaires différents. Dans des conditions de densité constante des proies, le modèle empirique IBM prédit de façon exacte ces différences de régime, ainsi que les différences qui en résultent dans la croissance larvaire et la probabilité de mourir de faim dans les divers systèmes. L'importance du comportement alimentaire pour la survie des larves diffère dans les petits lacs et dans le lac Michigan et ces résultats sont d'importance pour comparer la dynamique du recrutement dans des systèmes de grande et de petite taille.

[Traduit par la Rédaction]

\section{Introduction}

It is well-known that variability in mortality of larval fishes is often a significant factor driving variability in fishery recruitment (Sharp 1987). Mortality during the larval stage is affected by a variety of factors, including predation (Cowan and Houde 1993; Rice et al. 1993) and feeding success (Cushing 1990), and predicting larval mortality has proven elusive. In particular, interannual variation in survival of larval yellow perch (Perca flavescens) has been linked to pre-

Received 17 July 2004. Accepted 19 May 2005. Published on the NRC Research Press Web site at http://cjfas.nrc.ca on 24 November 2005.

$\mathrm{J} 18224$

Richard S. Fulford. ${ }^{1}$ Smithsonian Environmental Research Center, 647 Contees Wharf Road, Edgewater, MD 21037, USA. James A. Rice. Department of Zoology, North Carolina State University, Campus Box 7617, Raleigh, NC 27695, USA.

Thomas J. Miller. Chesapeake Biological Laboratory, University of Maryland Center for Environmental Sciences, P.O. Box 38, Solomons, MD 20688, USA.

Fred P. Binkowski. Great Lakes WATER Institute, 600 East Greenfield Avenue, Milwaukee, WI 53204, USA.

John M. Dettmers. Lake Michigan Biological Station, Illinois Natural History Survey, 400 17th Street, Zion, IL 60099, USA.

Brian Belonger. Wisconsin Department of Natural Resources, 101 N Ogden Road, Peshtigo, WI 54157, USA.

${ }^{1}$ Corresponding author (e-mail: fulfordr@si.edu). 
dation (Shroyer and McComish 2000), but the interaction of feeding success, growth, and survival has not been well described, particularly in larger systems.

Feeding success in fish larvae is affected by endogenous factors such as sensory ability (Blaxter 1986) and swimming performance (Webb and Weihs 1986; Fuiman et al. 1999) and by exogenous factors such as prey size and prey community composition (Kerfoot et al. 1980; DeVries et al. 1998). It is likely that larval fishes select prey based on a combination of these factors that is changing rapidly during ontogeny. Descriptions of larval diet based on endogenous factors only or on simplistic, exogenous models based only on prey size may fail to predict how changes in the prey community composition affect selection. Interactions of prey community structure with larval selectivity are particularly relevant for an analysis of feeding success of an opportunistic feeder such as larval yellow perch.

Yellow perch has a pelagic phase lasting 30-40 days that is generally associated with the ontogenetic period from hatch to the acquisition of juvenile characteristics, although the transition to demersal habitat generally occurs slightly later (Auer 1982). Yellow perch are widely distributed throughout North America in aquatic systems from 0.1 to $52000 \mathrm{~km}^{2}$ in area (Jenkins and Burkhead 1994). Such a wide range in habitat size suggests that perch may be exposed to a wide variety of foraging conditions throughout their distribution. Ontogenetic changes in taxonomic and size selectivity have been observed for larval perch within a variety of systems (surface area 0.1-392 $\mathrm{km}^{2}$, mean depth 5-12 m; Bulkley et al. 1976; Mills et al. 1984; Wahl et al. 1993). In a comparative study of two lakes, Siefert (1972) found that yellow perch larvae in a shallow eutrophic lake $\left(1.51 \mathrm{~km}^{2}\right.$, maximum depth $3.1 \mathrm{~m}$ ) followed a typical selective pattern, first feeding on copepod nauplii, then on copepodites, and finally on the larger copepods and cladocerans; however, perch larvae in a deeper, oligotrophic lake $\left(8.1 \mathrm{~km}^{2}\right.$, maximum depth $34 \mathrm{~m}$ ) selected for rotifers at first feeding and never showed positive selection for cladocerans. Such observed differences in selective pattern for larval perch between systems suggest that larval yellow perch can respond to variance in prey composition by changing their feeding behavior independent of ontogenetic development. Such plasticity in feeding behavior may be important to comparisons of larval feeding, growth, and survival between systems that differ in prey community composition.

Yellow perch larval feeding has been studied in lakes of widely varying sizes $\left(0.1-392 \mathrm{~km}^{2}\right)$, and prey community composition is not often cited as a potential cause of annual variation in survival for larval yellow perch within particular systems. Still, there are major differences between even the largest of these lakes and a more meso-oceanic system like Lake Michigan (52 $000 \mathrm{~km}^{2}$, mean depth $89 \mathrm{~m}$ ), such as the rotifer- and copepod-dominated zooplankton community of Lake Michigan (Madenjian et al. 2002), and more spatial variation in the abundance of larger zooplankton (Fulford 2003). The significance of these differences for comparisons of yellow perch feeding and growth between Lake Michigan and other systems, and the corresponding implications for larval survival, are unknown.

We conducted a series of laboratory experiments to quantify larval selectivity as a function of both larval size and prey type using a broader range of natural prey choices than has been used in previous selection studies on larval yellow perch. We then used these data to develop an empirical function designed to describe the diet of larval yellow perch with minimal assumptions regarding optimality of prey. This function combined Chesson's alpha $(\alpha)$ as a measure of the larval preference and prey community composition from field data as a measure of prey availability to predict prey selection of individual larva. We used this function to build an individual-based foraging and growth model (IBM) uniquely suited to addressing how differences among prey communities may affect foraging selectivity and diet of larval yellow perch. We used this IBM to ask how larval prey selection and diet may change between Lake Michigan and a smaller regional system (Green Bay) and how these differences may translate to differences in larval growth rate and survival between systems.

Green Bay (4212 $\mathrm{km}^{2}$, mean depth $20 \mathrm{~m}$ ) is a shallow, productive embayment connected to Lake Michigan at the Lake's northwest corner and has been the focus of research into the growth and survival of larval yellow perch (Bremigan et al. 2003). Green Bay is generally considered to be a large system, but it is closer to the small end of the spectrum in comparison with Lake Michigan and has a zooplankton composition similar to that observed in smaller systems described above, where yellow perch feeding selectivity has been studied, such as Oneida Lake, New York (Hansen and Wahl 1981; Mills and Forney 1981), and Lake Mendota, Wisconsin (Schael et al. 1991). Comparisons of perch foraging dynamics between the main body of Lake Michigan and Green Bay should be very informative regarding differences in larval yellow perch foraging behavior between different sizes of systems. Further, Green Bay is located adjacent to Lake Michigan and is exposed to similar regional conditions. The proximity of the two systems offers an opportunity to address differences between systems resulting from differences in system size without the confounding effect of larger-scale factors such as climate or geography.

\section{Methods}

\section{Selectivity experiments}

A population (hereafter main population) of yellow perch larvae was established in the laboratory from egg skeins collected in Lake Michigan. Skeins were manually stripped from ripe females collected in gill nets about $1.2 \mathrm{~km}$ from shore at a depth of 10-20 m. Collected skeins were fertilized in the boat with milt from three to six males and returned to the lab for incubation. Hatching occurred within 12-14 days of fertilization, and larvae were maintained in the lab in a $2.4 \mathrm{~m}$ diameter tank at $15-18{ }^{\circ} \mathrm{C}$ under flow-through conditions. Larvae were initially fed a tank culture of rotifers and small zooplankton four to six times per day. Starting 5 days posthatch (dph), larvae were fed Artemia nauplii four times per day. At $10 \mathrm{dph}$, food changed again to a commercial pellet fed four times per day from automatic feeders.

Zooplankton prey for the experiments were collected from two sites: nearshore Lake Michigan and Lake Nagawicka (3.7 $\mathrm{km}^{2}$, mean depth $\left.11 \mathrm{~m}\right)$, which is located 40 miles ( 1 mile $=1.609 \mathrm{~km})$ west of Milwaukee, Wisconsin. Zoo- 
plankton from nearshore Lake Michigan were collected $1.2 \mathrm{~km}$ from shore in waters $25 \mathrm{~m}$ deep by towing a $1 \mathrm{~m} \mathrm{di}$ ameter, $64 \mu \mathrm{m}$ mesh plankton net in a circular pattern $2 \mathrm{~m}$ below the surface. Two $15 \mathrm{~min}$ tows were completed at each of two sites about $1 \mathrm{~km}$ apart along the same depth contour. Zooplankton from Lake Nagawicka were collected at a single site $0.5 \mathrm{~km}$ from shore in waters $20-30 \mathrm{~m}$ deep as described above, with the exception that net diameter and tow length were reduced to $0.5 \mathrm{~m}$ and $5 \mathrm{~min}$, respectively. All zooplankton were returned to the lab and maintained under mild aeration.

Experimental trials were conducted in 2000 and 2001. The length range for larval yellow perch used in selectivity trials combined over both years was 5.5-35 $\mathrm{mm}$ total length (TL; 2-50 dph). In 2000, trials were conducted with three larval ages: 2 dph (mean length $=5.5 \mathrm{~mm}$, standard deviation $(\mathrm{SD})=0.41 \mathrm{~mm}), 15 \mathrm{dph}(8.6 \mathrm{~mm}, 0.91 \mathrm{~mm})$, and $30 \mathrm{dph}(12.3 \mathrm{~mm}, 1.4 \mathrm{~mm})$. To begin each trial, 200 larvae were transferred from the main population to each of five $38 \mathrm{~L}$ aquaria and allowed to acclimate for 7 days. These larvae were maintained at $15-18{ }^{\circ} \mathrm{C}$ under flowthrough conditions and were fed to satiation with live zooplankton collected from Lake Nagawicka for the first 5 days of the acclimation period. Feeding stopped on the sixth day of acclimation to ensure larvae would feed during the trial period and to allow pretrial zooplankton to be flushed from the system. Pretrial water samples indicated that no zooplankton remained in the trial tanks at the beginning of each trial period.

For this experiment, the objective was to present yellow perch larvae with as wide a range of prey choices as possible to assess larval selectivity under optimal conditions. Therefore, to begin a trial, Lake Nagawicka and nearshore Lake Michigan zooplankton were mixed equally and introduced into each trial tank at a target density of 250 organisms $\cdot \mathrm{L}^{-1}$. The number of zooplankton introduced into each tank was standardized based on zooplankton mass according to a predetermined mass-density relationship for mixed zooplankton (R. Fulford, unpublished data).

In 2001, trials were conducted at four larval ages: $15 \mathrm{dph}$ (mean length $=7.9 \mathrm{~mm}, \mathrm{SD}=0.6 \mathrm{~mm}), 30 \mathrm{dph}(11.6 \mathrm{~mm}$, $1.3 \mathrm{~mm}), 40 \mathrm{dph}(15 \mathrm{~mm}, 1.4 \mathrm{~mm})$, and $50 \mathrm{dph}(21.5 \mathrm{~mm}$, $3.0 \mathrm{~mm}$ ). Seven days prior to each trial date, larvae were moved from the main population to the trial tanks, and the acclimation process proceeded as described above for the 2000 trials. In 2001, we wished to measure larval selectivity changes in response to differences in the zooplankton community between nearshore Lake Michigan and an inland lake (Lake Nagawicka). Therefore the experimental system was expanded to 10 aquaria and two zooplankton treatments: nearshore Lake Michigan and Lake Nagawicka. Zooplankton from nearshore Lake Michigan and Lake Nagawicka were collected and maintained as described for the 2000 trials. For each trial, tanks containing acclimated larvae were randomly assigned to one zooplankton treatment or the other (nearshore Lake Michigan or Lake Nagawicka, $n=5$ per treatment). Zooplankton were introduced into each tank at a target density of 250 organisms $\cdot \mathrm{L}^{-1}$. The number of zooplankton introduced into each tank was standardized based on zooplankton mass and a predetermined mass-density relationship established separately for each treatment.
In both years, larvae were allowed to feed for $30 \mathrm{~min}$, and then they were removed from the tank, euthanized in tricaine methanesulfonate (MS-222), and preserved in 95\% ethanol for stomach analysis. Zooplankton were sampled at the beginning and end of each 30 min feeding trial by lowering a $4 \mathrm{~cm}$ diameter polyvinyl chloride tube onto four randomly placed rubber stoppers on the bottom of each tank to collect four replicate $250 \mathrm{~mL}$ samples. Collected zooplankton were preserved in $95 \%$ ethanol for identification and enumeration. Data collected were used to calculate larval diet selectivity and the difference in zooplankton composition between treatments. Zooplankton samples collected at the end of each trial were also used to check resource depletion during the trial period. The objective was to keep resource depletion to less than $50 \%$ in any single trial. Maximum proportion of zooplankton consumed during any trial was $40 \%$ (mean proportion $22 \%$ ).

\section{Sample analysis}

Mean total length on each trial day was calculated from length measured to the nearest $0.1 \mathrm{~mm}$ for 20 euthanized larvae from each trial tank. Stomach contents of preserved larvae $(n=30)$ were identified and enumerated by taxonomic group at $8 \times$ magnification. Taxonomic zooplankton groups were defined as rotifers, copepod nauplii, cyclopoid copepods, calanoid copepods, small cladocerans, and Daphnia spp. (Table 1). We chose to separate zooplankton into these groups based on consideration of differences in zooplankton size, morphology, and what is typically reported in the diet of larval yellow perch (Bulkley et al. 1976; Schael et al. 1991). The small cladoceran prey group was composed almost entirely of Bosmina spp. and Eubosmina spp. Lengths of whole prey items found in each stomach were measured to the nearest $0.1 \mathrm{~mm}$ with a digital imaging system (ImagePro 5.1, Media Cybernetics Inc., Silver Spring, Maryland).

Zooplankton in samples collected from each tank were also identified and enumerated by taxonomic group based on a complete count of samples $(n=8$ per tank) from both the beginning and end of the trial period. Mean size of zooplankton from the tanks was measured to the nearest $0.1 \mathrm{~mm}$ for common taxa with a digital imaging system. Differences in zooplankton community composition among treatments were examined with a MANOVA (multivariate analysis of variance) comparison (SAS Institute Inc. 2002).

\section{Diet selectivity}

Larval selectivity was quantified with the Chesson's $\alpha$ statistic (Chesson 1983). Selectivity of larva $k$ for prey type $i$ is defined as

$$
\alpha_{i, k}=\frac{r_{i, k} / p_{i}}{\sum_{j=1}^{m} r_{j, k} / p_{j}}
$$

where $r_{i, k}$ is the proportion of prey type $i$ in the gut of larva $k$, and $p_{i}$ is the proportion of prey type $i$ in the experimental tanks for $m$ different prey types. Lockwood (1998) recommended using proportional data rather than absolute number for each prey item in experiments where it is difficult to con- 
Table 1. Mean length and dry mass of the six larval prey types.

\begin{tabular}{|c|c|c|c|c|c|}
\hline Prey item & Length (mm) & Intercept $(a)$ & Exponent $(b)$ & Mass $(\mu \mathrm{g})$ & Reference \\
\hline Rotifers & 0.13 & 1.84 & 1.44 & 0.10 & Dumont 1975 \\
\hline \multicolumn{6}{|l|}{ Copepods } \\
\hline Nauplii & 0.2 & 3.0 & 1.71 & 0.19 & Culver et al. 1985 \\
\hline Calanoid & 0.54 & 6.19 & 1.96 & 1.85 & Culver et al. 1985 \\
\hline Cyclopoid & 0.43 & 6.66 & 2.89 & 0.58 & Culver et al. 1985 \\
\hline Small cladocerans ${ }^{a}$ & 0.3 & 17.74 & 2.22 & 1.2 & Culver et al. 1985 \\
\hline Daphnia spp. & 0.9 & 7.50 & 1.56 & 6.4 & Culver et al. 1985 \\
\hline
\end{tabular}

Note: Dry mass was calculated from mean length with relationships taken from the literature. Function used is mass $=a \times$ length ${ }^{b}$.

${ }^{a}$ Small cladocerans were predominantly from the genus Bosmina; the length-mass function used is for Bosmina longirostris.

trol for variation in total consumption with a timeindependent stopping rule.

Chesson's $\alpha$ is a useful metric of selectivity for modeling because it is numerically associated with a measure of attack and capture probability. Unlike some selectivity indices that have either a clear numerical or biological definition, Chesson's $\alpha$ has both and it can be used in the IBM to predict larval diet; this point will be expanded in a later section. Chesson's $\alpha$ was calculated for each individual fish $(n=$ 30 per tank), and a mean of these values for each tank represented a replicate value of $\alpha$ for each treatment $(n=5$ per treatment). For the analysis of selectivity patterns, selection was interpreted as neutral if the $95 \%$ confidence interval for $\alpha_{i}$ at a particular larval size included $m^{-1}$ and either positive or negative if the $95 \%$ confidence interval was higher or lower than $m^{-1}$, respectively.

\section{Zooplankton sampling}

Data regarding the zooplankton community of Lake Michigan were obtained from samples collected every 3 days from June to August in 2000 and 2001. Sampling was conducted with triplicate vertical hauls of a $0.5 \mathrm{~m}$ diameter, $64 \mu \mathrm{m}$ mesh plankton net at each of four sites between 1 and $5 \mathrm{~km}$ from shore. Samples were collected from the top $10 \mathrm{~m}$ of the water column at all sites. Zooplankton were preserved in $95 \%$ ethanol and returned to the lab for identification and enumeration of taxonomic groups (Table 1). Three $5 \mathrm{~mL}$ subsamples from each main sample were enumerated at $20 \times$ magnification in a counting wheel, and the combined count for all three subsamples was converted to density for each prey type based on a constant sample volume (sample depth $\times$ net mouth area).

Zooplankton community data for Green Bay were based on samples collected in 1998 and 1999. Samples were collected in a similar manner weekly in May and June at a site near Little Tail Point, Wisconsin (B. Belonger, unpublished data). The sampling period in Green Bay was earlier than in Lake Michigan because the larval period for yellow perch begins about a month earlier in Green Bay. Zooplankton were identified and enumerated as described for samples from Lake Michigan (J. Dettmers, unpublished data). Data from different years were used because comprehensive zooplankton data were not available for both systems in the same years. All zooplankton groups collected in zooplankton samples in Green Bay and Lake Michigan were present in collections used in laboratory experiments.

\section{Individual-based foraging model}

To examine the relationship between diet and growth for larval yellow perch, we adapted a general, larval fish, foraging IBM (Letcher et al. 1996) to predict growth and starvation rates of larval yellow perch from hatch to $45 \mathrm{dph}$ (Fig. 1). This model predicted daily consumption of each prey type (Table 1) for each individual larva $k$ based on larval length $(l, \mathrm{~mm})$ and a stochastic, sized-based encounter rate $\left(\mathrm{ER}_{i, k}\right)$, handling time $\left(\mathrm{HT}_{i, k}\right)$, and probability of attack and capture $\left(Q_{i, k}\right)$. Encounter rate and handling time were calculated using the general model with parameters specific to larval yellow perch (Table 2); full details of these calculations can be found in Fulford (2003).

Probability of attack and capture for larva $k$ on prey item $i$ in a given day was calculated in the model with an empirical function based on the Chesson's $\alpha$ metric and derived from our size-based selectivity experiments (Fig. 1). The probability that the next prey item attacked and captured by larva $k$ will be of prey type $i\left(Q_{i, k}\right)$ has two components: $(i)$ the selectivity of the larva defined empirically in our experiments and expressed as $\alpha_{i, k}$ and (ii) the relative abundance $p_{i}$ of prey type $i$ on a given model day.

The best-fit function between $\alpha_{i, k}$ and larval size (5$35 \mathrm{~mm}$ TL) was found separately for each prey type $i$ based on a comparison of the least-squared fit to the data for a series of common functions. Function types tested were linear, logarithmic, exponential, second-order polynomial, generalized logistic, and double Weibull.

Chesson's $\alpha$ is generally insensitive to changes in prey relative abundance; however, selectivity will always be near zero for any prey type when its relative abundance falls below a threshold value (Chesson 1983). When relative density for a particular prey item falls below this threshold, negative selectivity for that prey item will be indicated because larvae did not encounter this rare prey type, not because of prey type avoidance. Therefore, a threshold was defined as the relative abundance below which selectivity was always negative because of an absence of that prey item in larval guts; trials for which relative abundance of any prey item was less than the threshold were not used to fit the larval size - selectivity relationship for that prey item.

The best function for each prey type was based on a coefficient of multiple determination $\left(R_{\mathrm{a}}^{2}\right)$ adjusted for the number of parameters in the model (Neter et al. 1990). The bestfit function for each prey type $i$ was then used in the IBM to predict $\alpha_{i, k}$ for prey type $i$. Data used for calculations of $\alpha_{i, k}$ for larvae larger than $25 \mathrm{~mm}$ TL included diet and field zoo- 
Fig. 1. Flow chart summarizing the individual-based model for foraging and growth used for the numerical experiments. Starvation threshold was set at $53 \%$ of previous maximum dry mass for all model simulations.
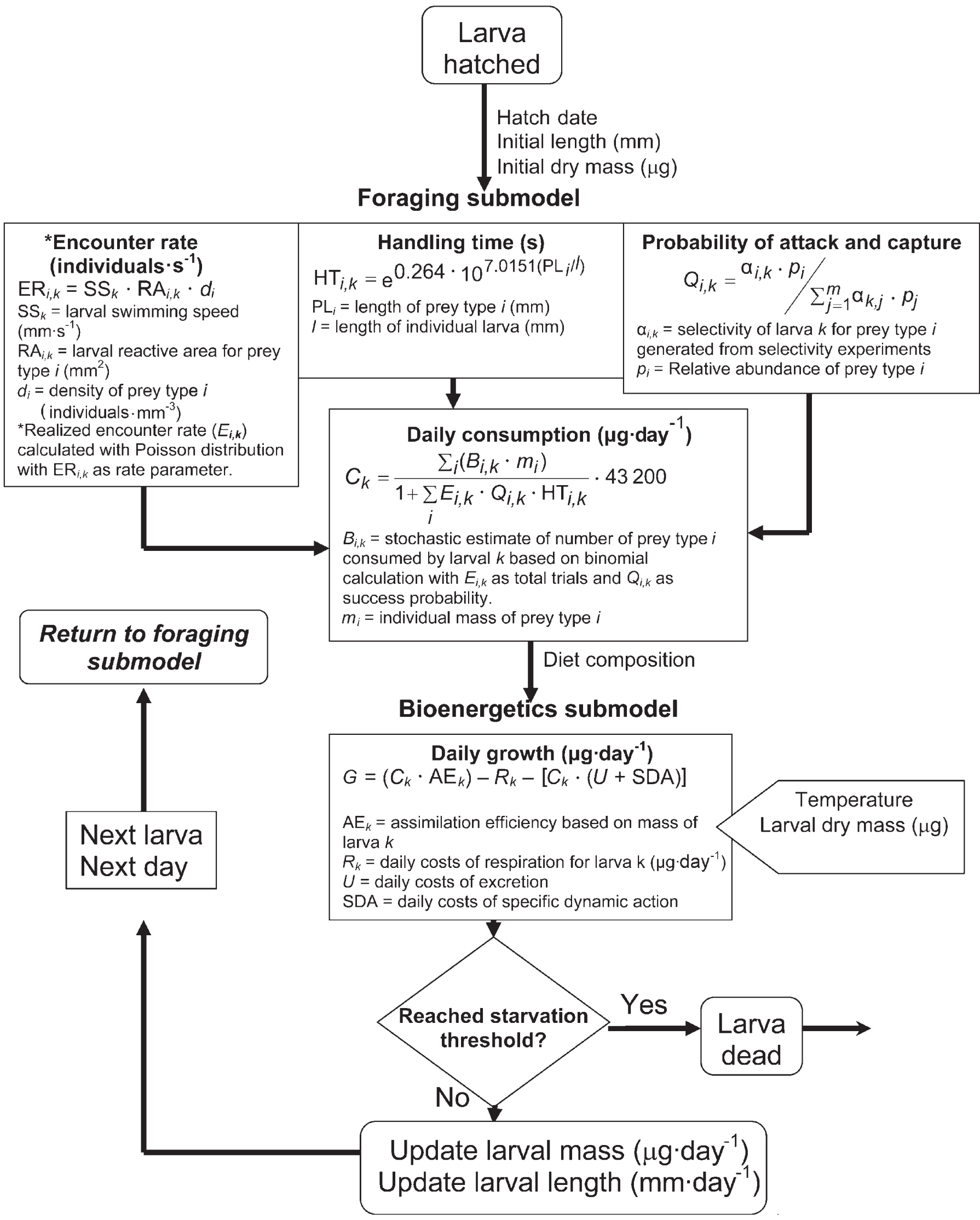
Table 2. Calculations used in the individual-based model (IBM) for larval swimming speed (SS, $\mathrm{mm} \mathrm{s}^{-1}$ ), larval reactive area $\left(\mathrm{RA}, \mathrm{mm}^{2}\right)$, larval daily metabolic cost $\left(R_{k}, \mu \mathrm{g}\right.$ day $\left.^{-1}\right)$, larval assimilation efficiency (AE), and larval dry mass-to-length conversion ( $W_{k}$ $(\mu \mathrm{g})$ to length $(\mathrm{mm}))$.

\begin{tabular}{|c|c|c|c|}
\hline Model parameter & Submodel & Function & Source \\
\hline Swimming speed & Foraging & $\begin{array}{l}\text { Hatch } 8 \mathrm{~mm} \text { TL: } 1 \text { body length } \cdot \mathrm{s}^{-1} \\
>8 \mathrm{~mm} \text { TL: } 3 \text { body lengths } \cdot \mathrm{s}^{-1}\end{array}$ & Houde 1969 \\
\hline $\begin{array}{l}\text { Reactive area of larval } k \text { for } \\
\text { prey type } i\end{array}$ & Foraging & $\mathrm{RA}_{i, k}=\left[\frac{\mathrm{PL}_{i}}{2 \tan \left(a_{k} / 2\right)}\right]^{2} \pi \cdot 0.5$ & Letcher et al. 1996 \\
\hline Daily metabolic cost & Bioenergetics & $R_{k}=W_{k} \cdot 0.0065 \cdot \mathrm{W}_{k}^{-0.2} \cdot f(t) \cdot 4.4$ & Hanson 1997 \\
\hline Length - dry mass relationship & $\begin{array}{l}\text { Initial inputs } \\
\text { Bioenergetics }\end{array}$ & $W_{k}=0.519$ length $^{3.293}$ & $\begin{array}{l}\text { Mills and Forney 1981; } \\
\text { C. Heyer }{ }^{a}, \text { T. Miller }^{b} \text {, } \\
\text { and B. Letcher }{ }^{c} \text { unpub- }^{\text {lished data }}\end{array}$ \\
\hline
\end{tabular}

Note: Larval length is total length (TL) and Hatch refers to total length at time of hatching. PL ${ }_{i}$, length (mm) of prey type $i$; $a_{k}$, angle (radians) of visual acuity for a larva of length $k ; f(t)$, relationship between water temperature $\left(t,{ }^{\circ} \mathrm{C}\right)$ and daily metabolic cost. The function $f(t)$ and the formula for $a_{k}$ are defined in Fulford (2003).

${ }^{a}$ Maryland Department of Natural Resources, Annapolis, MD 21401.

${ }^{b}$ University of Maryland Center for Environmental Science, Solomons, MD 20688.

${ }^{c}$ Conte Anadromous Fish Research Center, USGS/BRD, Turner Falls, MA 01376.

plankton data from the literature (Bulkley et al. 1976; Mills et al. 1984). Diet selectivity indices were calculated for yellow perch in these studies, but in cases where the index was not Chesson's $\alpha$, we converted the selectivity index to Chesson's $\alpha$. In the model, $Q_{i, k}$ is calculated each day for each larva $k$ and each available prey item $i$.

The number of each prey type consumed in a given day was then converted to mass ( $\mu \mathrm{g}$ dry mass) by multiplying the number of each prey type $i$ eaten in a day by the mean mass of prey type $i$. Mean mass for each prey type was derived from a prey type specific, length-mass relationship and mean length for each prey type taken from zooplankton collected in Lake Michigan (Table 1). Zooplankton relative abundance in the model was based on the average seasonal pattern observed during the yellow perch larval period over 2 years for each prey type taken from the field data for either Green Bay or Lake Michigan. Zooplankton density was manipulated as a part of the numerical experiments (described below).

\section{Individual-based bioenergetics model}

Total mass consumed by larva $k$ each day was converted to individual daily growth ( $\mu \mathrm{g}$ dry mass) in a bioenergetics submodel adapted from two models: one developed previously for larval yellow perch (Hanson 1997) and a general larval bioenergetics model developed specifically for an IBM approach (Letcher et al. 1996). The combined model uses a mass-balance approach to predict daily growth $(G$, $\left.\mu \mathrm{g} \cdot \mathrm{day}^{-1}\right)$ from predicted daily consumption $\left(C, \mu \mathrm{g} \cdot \mathrm{day}^{-1}\right)$ from the foraging submodel (Fig. 1). Larval mass was updated daily based on predicted growth. During a model run, a larva could not lose length but could lose mass based on the difference between total daily consumption predicted by the foraging submodel and calculated daily metabolic costs. If a larva lost more than $53 \%$ of its previous maximum mass at any point in a model run, then that larva starved to death. If larval mass increased beyond the previous maximum value for larva $k$, length was updated based on a length-mass con- version (Table 2). Full details regarding the bioenergetics model used are available in Fulford (2003).

Input to the bioenergetics submodel was daily mean water temperature and current dry mass of larva $k$. Daily mean temperature data were taken from a variety of sources depending on the system being modeled. Temperature data for nearshore Lake Michigan were taken from hourly temperature records collected $1 \mathrm{~m}$ below the surface at a site located $1.2 \mathrm{~km}$ from shore due east of Texas Rock near Milwaukee, Wisconsin $\left(42^{\circ} 59^{\prime} 60^{\prime \prime} \mathrm{N}, 87^{\circ} 50^{\prime} 38^{\prime \prime} \mathrm{W}\right)$, from June to August 1999-2001 (R. Fulford, unpublished data). Temperature data for Green Bay were taken from temperature data collected hourly at the surface of the intake canal for the Pulliam power plant in Green Bay, Wisconsin, and from weekly temperature measurements taken at the surface $0.5 \mathrm{~km}$ from shore near Little Tail Point on the southwestern side of Green Bay. Little Tail Point is located $15 \mathrm{~km}$ north of the City of Green Bay. The area around Little Tail Point is a known spawning area for yellow perch (B. Belonger, unpublished data).

Each model simulation began with 1000 larvae, and initial size was randomly assigned to each larva from a normal distribution $($ mean $=5.7 \mathrm{~mm}, \mathrm{SD}=0.3 \mathrm{~mm}$ ). Initial mass was calculated from randomly assigned length according to a larval yellow perch specific mass-length formula (Table 2). Model output was larval size-specific diet data, individual and cohort mean growth rate over the period from hatch to 45 days, distribution of size at age for the entire cohort, and the proportion of larvae that starved to death during each model run.

\section{Numerical experiments}

We conducted two numerical experiments with the foraging and growth IBM to address two questions. First, we wanted to establish that the model would accurately predict diet for larvae exposed to different prey assemblages. To accomplish this, the functions relating $\alpha_{i, k}$ to larval TL were fit to a subset of the data from selectivity trials $(n=45$ tri- 
als). We then used the model to predict the diet of larvae exposed to the prey assemblage in the remaining set of reference data ( $n=10$ trials). The reference data were for larvae between 7 and $15 \mathrm{~mm}$ TL and were broken into two sets: larvae exposed to a zooplankton community from nearshore Lake Michigan and larvae exposed to a zooplankton community from Lake Nagawicka. These predictions were then compared with a $\chi^{2}$ analysis to observed diet for larvae used in the reference trials.

Second, we asked how larval growth rate, size at age, and likelihood of starvation are affected by differences in zooplankton community composition between Green Bay and Lake Michigan. The model was run with two separate prey assemblages consisting of zooplankton composition observed in nearshore Lake Michigan in 2000-2001 or in Green Bay in 1998-1999. Simulations were conducted at 50, 100, 150, 200, and $250 \mathrm{prey} \cdot \mathrm{L}^{-1}$ for each zooplankton assemblage. A broad range of zooplankton densities was used to explore more generally relevant patterns in growth and survival as a function of prey density than observed in just the 2 years for which we had data. We also wanted to explore more directly how the interacting effects of prey density and composition on larval growth and starvation mortality differ between nearshore Lake Michigan and Green Bay. The range of zooplankton density used in this experiment approximates the full range of daily and site-specific mean zooplankton densities observed in both nearshore Lake Michigan and Green Bay (Fulford 2003; J. Dettmers, unpublished data). Three replicate model runs were conducted for each combination of zooplankton density and zooplankton assemblage to account for variability due to stochastic functions in the model.

\section{Results}

\section{Selectivity experiments}

The three zooplankton assemblages used in selectivity trials (nearshore Lake Michigan, Lake Nagawicka, and mixed) differed significantly in composition (Wilks' $\lambda F_{[12,94]}=$ 12.34, $p<0.0001)$. The Lake Michigan treatment was dominated $(>70 \%)$ by rotifers, while the Lake Nagawicka assemblage was composed largely of Daphnia spp. and cyclopoid copepods. The mixed assemblage was the most balanced among prey types but remained high in rotifers $(>40 \%)$. Mean initial zooplankton density in the trials tanks was 382 prey $\cdot \mathrm{L}^{-1}$ and ranged from 112 to $782 \mathrm{prey} \cdot \mathrm{L}^{-1}$. The higher than expected mean and variance in zooplankton density in the tanks was due largely to variance in rotifer density, because rotifers can vary in number without having much affect on total mass of a zooplankton sample. However, high zooplankton density in the tanks should not bias our measurements of selectivity as long as density is high enough to generate larval feeding activity.

Values of $\alpha$ for rotifers indicated strong positive selection by $5.5 \mathrm{~mm}$ larvae, but dropped quickly to near zero, indicating negative selection at all larger larval sizes (Fig. 2a). Values of $\alpha$ for copepod nauplii were also highest for larvae at $5.5 \mathrm{~mm}$ TL, but selection was neutral rather than positive. Selection for nauplii was generally neutral up to $15 \mathrm{~mm}$ TL, and $\alpha$ values showed no trend with size (Fig. 2a).
Fig. 2. Chesson's $\alpha$ for larval yellow perch (Perca flavescens) feeding on $m=6$ prey types: $(a)$ rotifers $(\boldsymbol{\Delta})$ and copepod nauplii $(\triangle),(b)$ calanoid $(\diamond)$ and cyclopoid copepods $(\diamond)$, and (c) small cladocerans ( ) and Daphnia spp. (O). The horizontal broken line represents no selection and is set at $\mathrm{m}^{-1}$. Symbols are offset by +0.5 (open) or -0.5 (solid) on the $x$ axis for clarity. TL, total length.
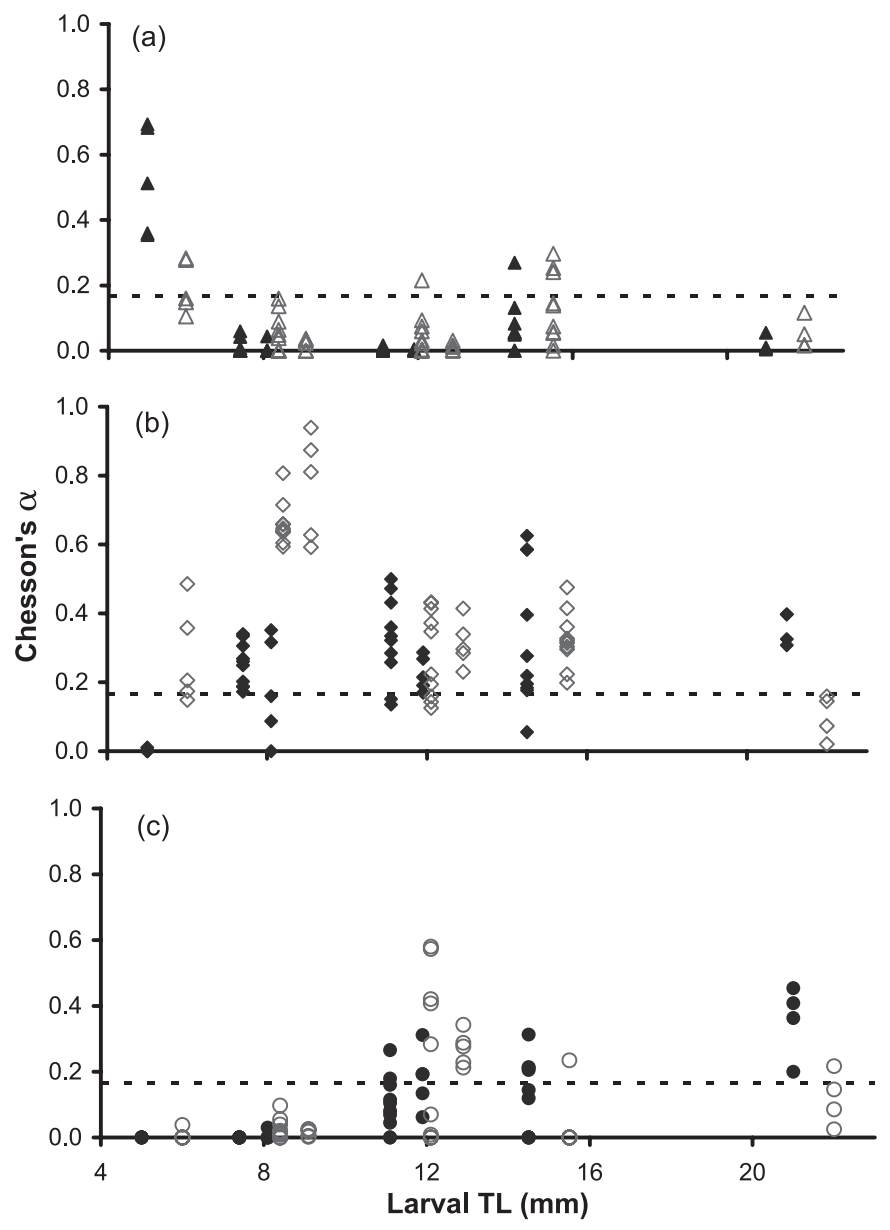

Selection differed for cyclopoid and calanoid copepods (Fig. 2b). Values of $\alpha$ for cyclopoid copepods were initially neutral but rose sharply for larvae at $8 \mathrm{~mm}$ TL, indicating a period of strong positive selection by early-feeding larvae. Larval selection for cyclopoid copepods was neutral for larvae larger than $12 \mathrm{~mm}$ TL. Data from the literature used in the model also suggest that selectivity for cyclopoid copepods by yellow perch larvae at $26.5 \mathrm{~mm}$ TL is neutral (Bulkley et al. 1976).

Selection for calanoid copepods was negative for yellow perch larvae at $5.5 \mathrm{~mm}$ TL. Values of $\alpha$ rose with larval size beginning around $8 \mathrm{~mm}$ TL and were generally positive for larvae larger than $12 \mathrm{~mm}$ TL (Fig. 2b). Data from the literature used in the model suggest that selection for calanoid copepods by larvae at 26.5 and $35 \mathrm{~mm}$ TL is consistently positive (Bulkley et al. 1976; Mills et al. 1984).

Selectivity patterns for cladocerans all showed similar patterns with slightly different shapes (Fig. 2c). Selectivity for small cladocerans was negative for all larvae less than $12 \mathrm{~mm}$ TL, became neutral for larvae between 12 and 
Table 3. Summary of the model fit between Chesson's $\alpha$ and larval total length $(L, \mathrm{~mm})$ for each prey type based on experimental data.

\begin{tabular}{|c|c|c|c|}
\hline Prey Item & Model type & Parameters & $R^{2}$ \\
\hline Rotifers & Power: $\alpha=a L^{b}$ & $\begin{array}{l}a=193499 \\
b=-7.64\end{array}$ & 0.89 \\
\hline \multicolumn{4}{|l|}{ Copepods } \\
\hline Nauplii & No trend & Mean $\alpha=0.07$ & NA \\
\hline Cyclopoid & Polynomial: $\alpha=a_{1} L^{2}+a_{2} L+a_{3}$ & $\begin{array}{l}a_{1}=-0.042 \\
a_{2}=0.75 \\
a_{3}=-2.60\end{array}$ & 0.67 \\
\hline Calanoid & Log-linear: $\alpha=a \ln (L)+b$ & $\begin{array}{l}a=0.272 \\
b=-0.3834\end{array}$ & 0.68 \\
\hline Small cladocerans & Logistic: $\alpha=\frac{a_{1}}{\left[1+\left(\frac{a_{1}}{a_{2}}-1\right) \mathrm{e}^{-a_{3} a_{4} L}\right]^{1 / a_{4}}}$ & $\begin{array}{l}a_{1}=0.40 \\
a_{2}=0.09 \\
a_{3}=13 \\
a_{4}=0.031\end{array}$ & 0.65 \\
\hline Daphnia spp. & Logistic: $\alpha=\frac{a_{1}}{\left[1+\left(\frac{a_{1}}{a_{2}}-1\right) \mathrm{e}^{-a_{3} a_{4} L}\right]^{1 / a_{4}}}$ & $\begin{array}{l}a_{1}=0.445 \\
a_{2}=0.092 \\
a_{3}=20 \\
a_{4}=0.029\end{array}$ & 0.86 \\
\hline
\end{tabular}

Note: Larval size range was $5.5-35 \mathrm{~mm}$ total length for all functions, and data for larvae $>25 \mathrm{~mm}$ total length includes data from the literature.

$15 \mathrm{~mm}$ TL, and was positive for larvae greater than $21.5 \mathrm{~mm}$ TL. Data from the literature (Bulkley et al. 1976) suggest that values of $\alpha$ for larvae between 26 and $35 \mathrm{~mm}$ TL are above $m^{-1}$, indicating that selection for small cladocerans by yellow perch larvae larger than $21.5 \mathrm{~mm}$ is consistently positive.

Larval selectivity for Daphnia spp. was negative for larvae at 5.5 and $8 \mathrm{~mm}$ TL, but neutral or positive at 11.6 and $12.2 \mathrm{~mm}$ TL (Fig. 2c). Values of $\alpha$ for larger larvae did not rise above $m^{-1}$ in this experiment, but mean relative density of Daphnia spp. only ranged from $0.01 \%$ to $0.03 \%$ in replicate tanks at all larger larval sizes tested. These low density values suggest that negative selection in these trials for Daphnia spp. was due to low encounter rates rather than larval preference. Selectivity data from the literature used in the model for larvae at 26.5 and $35 \mathrm{~mm}$ TL suggest positive selection for Daphnia spp. by larger larval yellow perch (Mills et al. 1984; Schael et al. 1991).

\section{Parameterizing the IBM}

Based on the selectivity data, the relative abundance minimum threshold for inclusion in the function was set at $0.03 \%$. When relative abundance of a particular prey item in a trial was below $0.03 \%$ of the assemblage, data from that trial were not used to fit the larval size - selectivity relationship for that prey item.

No single function fit the data relating Chesson's $\alpha$ to larval TL best for all six prey types (Table 3). Selectivity for rotifers was best described by a power function (Fig. $3 a$ ). The model fit was highest for rotifers among all prey types. We observed no relationship between larval selectivity for copepod nauplii and larval size; selectivity for nauplii in the model was described with the mean value of $\alpha$ for nauplii across all larval sizes (0.07; Fig. $3 b)$. Selectivity for cyclo- poid copepods was best described by a second-order polynomial function with a minimum $\alpha$ level set at $m^{-1}$ (Fig. 3c). This function allowed for the steep rise in $\alpha$ for larvae around $8 \mathrm{~mm}$ TL and predicted neutral selection for larvae larger than $12 \mathrm{~mm}$ TL. Selectivity for calanoid copepods was best described by a logarithmic regression, with a maximum $\alpha$ value of 0.4 for larvae larger than $15 \mathrm{~mm}$ TL (Fig. 3d). Selectivity for both small cladocerans and Daphnia spp. was best described by a generalized logistic function (Figs. 3e, $3 f$ ). Values of $\alpha$ for both cladoceran groups were low initially and rose with increasing larval size.

\section{Zooplankton community composition}

The nearshore Lake Michigan zooplankton assemblage was dominated numerically by rotifers (80\%; Fig. $4 a$ ). Prey densities across sites in nearshore Lake Michigan in 2000-2001 were between 50 and $200 \mathrm{prey} \cdot \mathrm{L}^{-1}$, with a 2-year mean density of 75 prey. $\mathrm{L}^{-1}$. In contrast, the prey assemblage of Green Bay was more diverse. Cladocerans and copepods were nearly equal in abundance, and no prey type represented more than $50 \%$ of the total assemblage at any time over the larval period (Fig. 4b). Prey densities in 1998-1999 in Green Bay were between 50 and $300 \mathrm{prey} \cdot \mathrm{L}^{-1}$, with a 2year mean density of 124 prey $\cdot \mathrm{L}^{-1}$ over both years.

\section{Numerical experiments}

In experiment one, model predictions of diet for larvae feeding on a nearshore Lake Michigan or Lake Nagawicka zooplankton assemblage did not differ significantly from observed diet $\left(\chi^{2}=1.23\right.$, degrees of freedom $\left.(\mathrm{df})=5, p>0.1\right)$, which suggests the model performed well (Fig. 5). Diets for larvae exposed to the nearshore Lake Michigan assemblage were dominated by calanoid and cyclopoid copepods, with rotifers and cladocerans being a minor dietary component. In 
Fig. 3. Chesson's $\alpha$ data $(\diamond)$ and best model fit to the data for a prey type specific function (solid line) relating Chesson's $\alpha$ to larval total length (TL, mm) for $(a)$ rotifers, $(b)$ copepod nauplii, $(c)$ cyclopoid copepods, $(d)$ calanoid copepods, $(e)$ small cladocerans, and (f) Daphnia spp. as prey. Error bars for data are $95 \%$ confidence intervals.
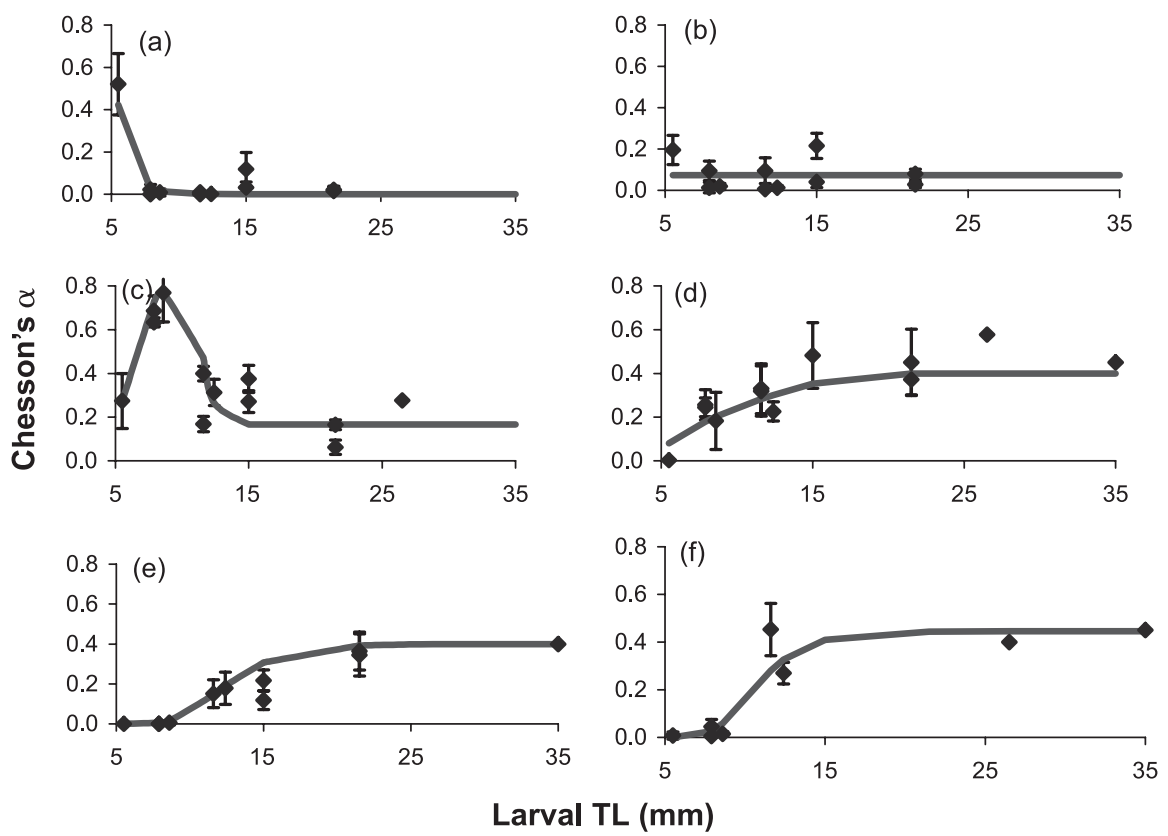

contrast, diets of larvae exposed to the Lake Nagawicka assemblage were composed mostly of Daphnia spp., with calanoid copepods a distant second in relative dietary abundance. There were noticeable differences between what was available to and what was eaten by larvae, particularly for the nearshore Lake Michigan treatment, where larvae avoided rotifers despite their high relative abundance. However, available prey composition did not differ significantly from either observed diet or model predictions $\left(\chi^{2}=1.3\right.$, $\mathrm{df}=5$, $p>0.1)$.

In experiment two, larvae exposed to the nearshore Lake Michigan assemblage in the model fed mainly on rotifers and copepods initially and made a transition to mainly larger calanoid copepods as they grew, mainly at the expense of rotifers (Fig. 6a). Larvae exposed to the Green Bay assemblage in the model fed largely on cyclopoid copepods initially, avoided the smaller rotifers, and shifted gradually to a diet split between small cladocerans and Daphnia spp. as they increased in size. The transition to small cladocerans and Daphnia spp. was predicted to occur around $20 \mathrm{~mm}$ TL, and these two items dominated larval diet in Green Bay for the remainder of the model run (Fig. 6b).

These observed differences in diet between larvae exposed to different prey assemblages translated into differences in both growth and survivorship in the model. Larvae allowed to forage on the Green Bay assemblage had a higher predicted mean growth rate compared with nearshore Lake Michigan larvae at all prey densities except the lowest $\left(50\right.$ prey $\left.\cdot \mathrm{L}^{-1}\right)$. Growth rates for larvae exposed to the nearshore Lake Michigan assemblage did not rise substantially until prey density rose above 100 prey $\cdot \mathrm{L}^{-1}$ (Fig. 7). Growth rates for larvae exposed to the Green Bay prey assemblage were also low at a density of $50 \mathrm{prey} \cdot \mathrm{L}^{-1}$ but rose more rapidly between 50 and 200 prey $\cdot \mathrm{L}^{-1}$. Further, more than $50 \%$ of simulated larvae exposed to the nearshore Lake
Michigan assemblage starved at prey densities fewer than 150 prey L $^{-1}$ (Fig. 8). Starvation rates for larvae exposed to the nearshore Lake Michigan assemblage declined linearly with increasing prey density over the entire density range (50-250 prey $\left.\cdot \mathrm{L}^{-1}\right)$. In contrast, larvae exposed to the Green Bay assemblage had a high starvation rate at the lowest density, but it dropped rapidly to around $20 \%$ or lower for prey densities at or above $150 \mathrm{prey} \cdot \mathrm{L}^{-1}$ (Fig. 8).

These differences in growth and survivorship were reflected in larval size distributions at the end of the model runs. Larval survivors that fed on the Green Bay prey assemblage (Figs. 9b, 9d) had a wider size range and were generally larger than larval survivors that fed on the nearshore Lake Michigan assemblage (Figs. $9 a, 9 c$ ) at the same prey density. At a prey density of 250 prey $\cdot \mathrm{L}^{-1}$, both distributions were bimodal, but the major mode in the length distribution for larvae exposed to the Green Bay assemblage (mode centered on $34 \mathrm{~mm}$ TL) included most of the larval survivors. The minor mode in the length distribution of the Green Bay assemblage (at $20 \mathrm{~mm}$ TL) overlapped the major mode in the length distribution of the nearshore Lake Michigan assemblage (at $\sim 18 \mathrm{~mm}$ TL). The minor mode in the length distribution of larval survivors exposed to the nearshore Lake Michigan assemblage ( $7 \mathrm{~mm}$ TL) was composed of larvae demonstrating little or no growth over the model period. In contrast, the minor mode of larvae exposed to the Green Bay assemblage was composed of larvae that grew substantially.

The size distribution of larval survivors exposed to both prey assemblages at a lower mean density $\left(100 \mathrm{prey} \cdot \mathrm{L}^{-1}\right)$ had similar length ranges as observed at the higher prey density, but the peak in larval size dropped 5 and $13 \mathrm{~mm}$ for larval exposed to the nearshore Lake Michigan and Green Bay assemblages, respectively (Figs. $9 a, 9 b$ ). In the case of larvae exposed to the nearshore Lake Michigan assemblage, the 
Fig. 4. Relative abundance of six prey types in field samples collected during the pelagic larval period for yellow perch (Perca flavescens) in (a) nearshore Lake Michigan and (b) Green Bay. From the bottom of each panel to the top, the prey items are rotifers, nauplii, calanoids, cyclopoids, small cladocerans, and Daphnia spp.

(a)

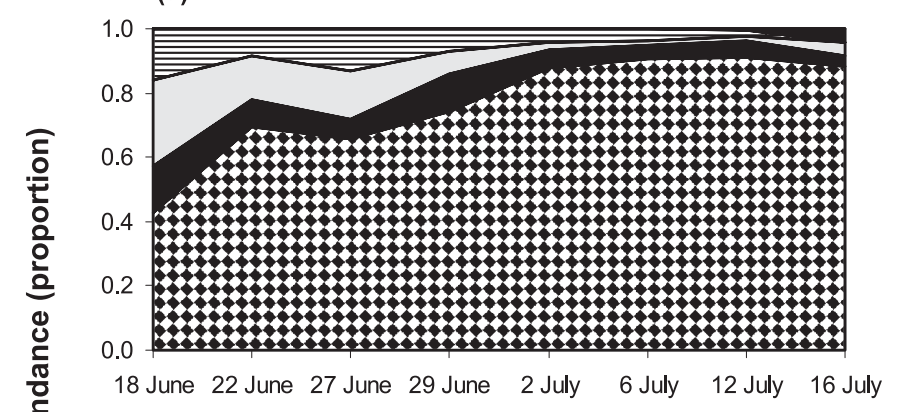

(b)

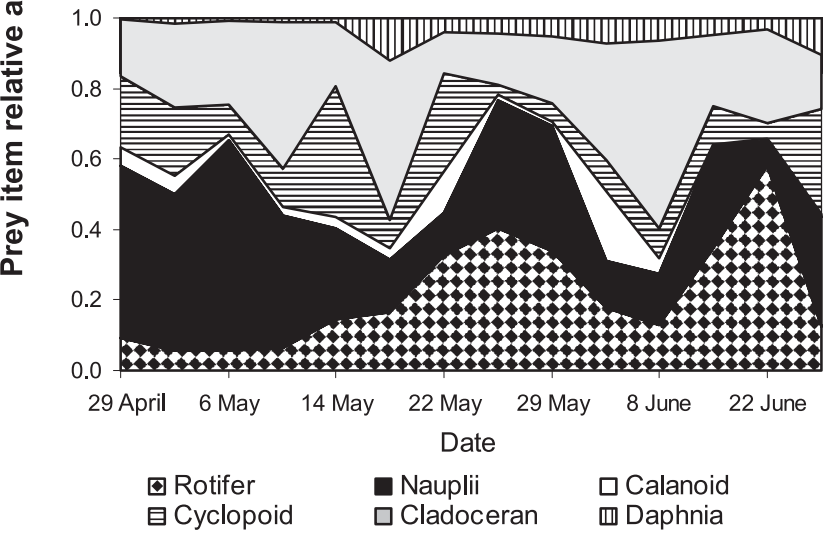

distribution was no longer bimodal, as observed in this distribution at the higher prey density.

\section{Discussion}

\section{Diet shifts and community composition}

Larval yellow perch appear to make three distinct transitions in selection throughout ontogeny: from rotifers to small copepods to large copepods and cladocerans. However, the first and last transitions seem most dependent on prey community composition.

Larval yellow perch initially showed positive selection for rotifers in our selectivity experiments. This early preference for rotifers has been observed in field data from other oligotrophic systems (Siefert 1972). Surprisingly, a preference for rotifers appears to lower predictions of larval survival. Larvae that switched to small copepods at a smaller size in the model had a distinct growth advantage over larvae that fed largely on rotifers, but this energetic conclusion does not appear to translate to a high preference for copepods in early-stage larvae. Low or negative growth for yellow perch larvae that have been fed rotifers has been observed previously in laboratory experiments (Graeb et al. 2004).

It could be that first-feeding larval yellow perch select rotifers simply because they are much more abundant and easy to catch and that this initial positive selection is dependent
Fig. 5. Comparison of observed diet ( \pm 1 standard error; open bars), diet predicted by our individual-based foraging model (solid bars), and prey availability (hatched bars) for larval yellow perch (Perca flavescens; 7-15 mm total length) exposed to a prey assemblage from either $(a)$ nearshore Lake Michigan or $(b)$ Lake Nagawicka.

(a)

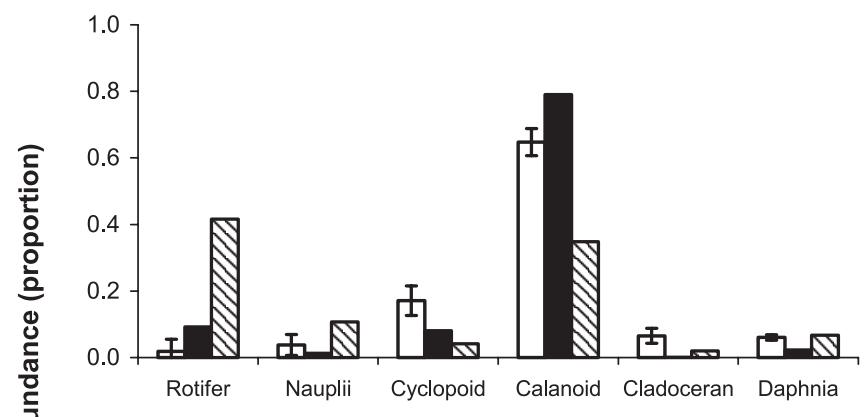

(b)

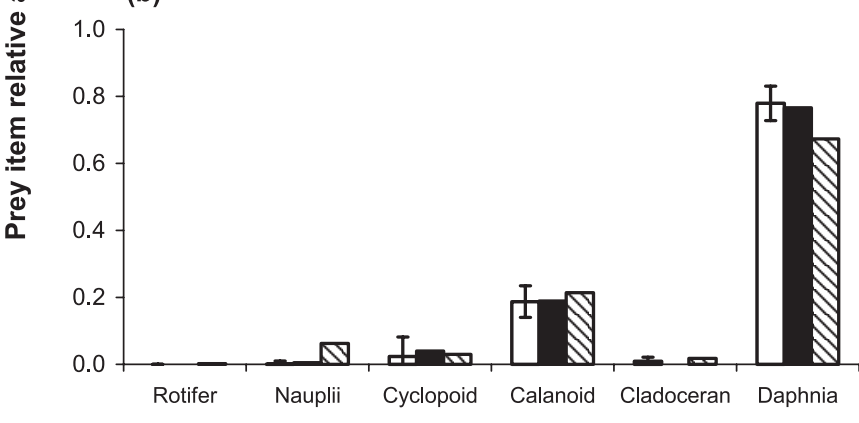

Prey group

on limited foraging ability rather than true preference. The full recruitment of visual acuity occurs after first feeding in larval yellow perch (Wahl et al. 1993); first-feeding larvae are likely to select prey based on a more immediate definition of optimality (i.e., avoiding starvation). Model results do predict that larvae exposed to the Green Bay prey community (i.e., low rotifer abundance) will switch to small copepods earlier than larvae exposed to a nearshore Lake Michigan prey community (i.e., high rotifer abundance), and early-stage larvae feeding on copepods have a major growth advantage over larvae that are not. Such selective choices demonstrate the difference between the long- and short-term optimality of foraging decisions. In the short term, it is clearly optimal to eat rotifers rather than nothing at all. However, in the long term, larvae that shift to higher value prey will grow faster and are more likely to survive the larval stage. Model predictions suggest that larvae that fail to make this early transition may be trading a death from starvation for a death by size-selective processes (i.e., predation) and are no more likely to contribute to the year class than larvae that eat nothing at all.

The final transition in larval diet prior to the beginning of the juvenile stage involves a community-dependent trade-off between larger copepods and cladocerans. Larval perch were predicted to select for cladocerans at intermediate larval sizes even when cladocerans comprised only $1 \%$ of the prey assemblage. However, the nearshore Lake Michigan prey assemblage frequently had less than half a percent cladocerans in 2000-2001, and larvae exposed to this prey community in 
Fig. 6. Mean diet composition for larval yellow perch (Perca flavescens) from model runs ( $N=3,1000$ larvae per run) exposing larvae to a zooplankton assemblage from either $(a)$ nearshore Lake Michigan or $(b)$ Green Bay. From the bottom of each panel to the top, the prey items are rotifers, nauplii, calanoids, cyclopoids, small cladocerans, and Daphnia spp. Not all prey items are visible in a single panel.

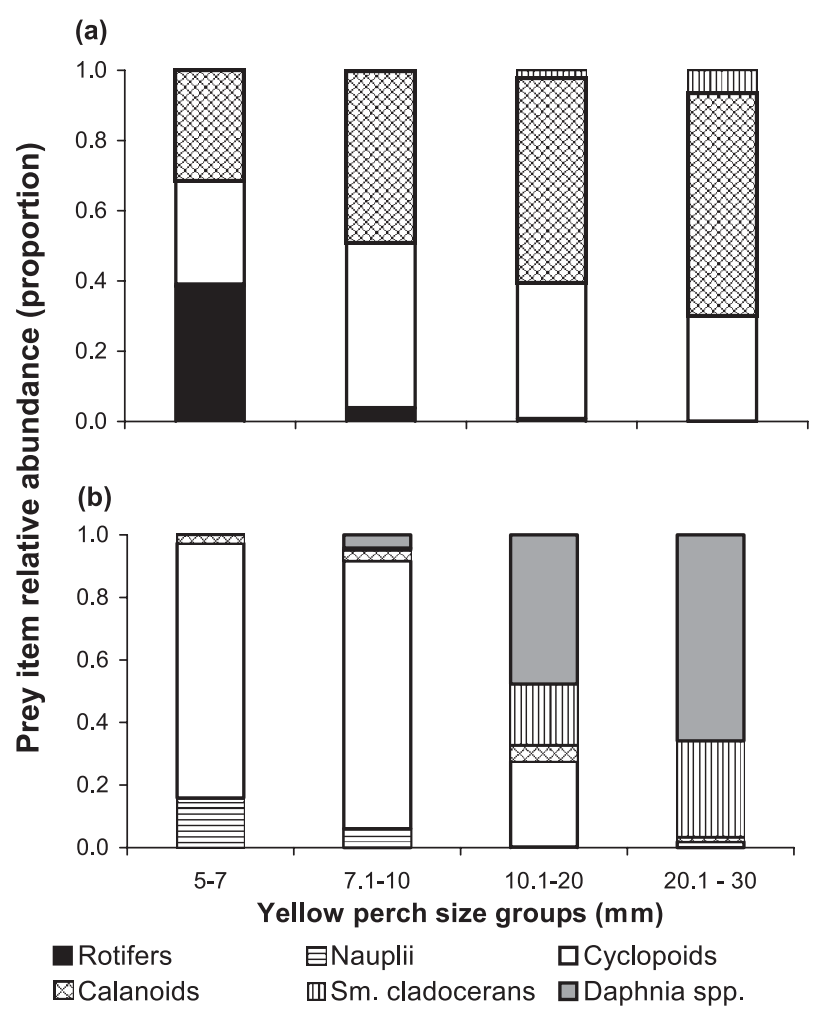

the model shifted their selection to larger calanoid copepods. Larval yellow perch larger than $16 \mathrm{~mm}$ TL showed positive selection for calanoid copepods in all assemblages, but the importance of calanoids tended to vary based on the relative abundance of cladocerans.

Laboratory experiments have demonstrated that late-stage larval perch positively select for calanoid copepods and incur a growth advantage by doing so (Confer and Lake 1987). Nevertheless, positive selection for cladocerans has been consistently observed for yellow perch larvae in field data from other systems, including Lake Mendota (Schael et al. 1991) and Oneida Lake (Hansen and Wahl 1981; Mills et al. 1984), but the timing of this transition with respect to larval size varies greatly. Variance in the observed onset of positive selection for Daphnia spp. may be due in part to variance in the composition of the Daphnia complex between systems. Daphnia spp. collected in Green Bay, Lake Nagawicka, and nearshore Lake Michigan were mainly medium-bodied Daphnia spp. (0.62-1.17 mm). In contrast, Oneida Lake is dominated by Daphnia pulex, which has a size range of $0.7-$ $2.1 \mathrm{~mm}$ (Mills et al. 1984). Positive preference for Daphnia spp. was evident at a smaller larval size in our data compared with similar data from other systems; this difference is most likely due to observed differences in the size of the Daphnia complex. Such differences are an important reason
Fig. 7. Mean growth rate from model runs comparing larvae exposed to a zooplankton assemblage from nearshore Lake Michigan $(\bullet)$ or Green Bay $(\triangle)$ over a range of zooplankton densities. $N=1000$ larvae per model run.

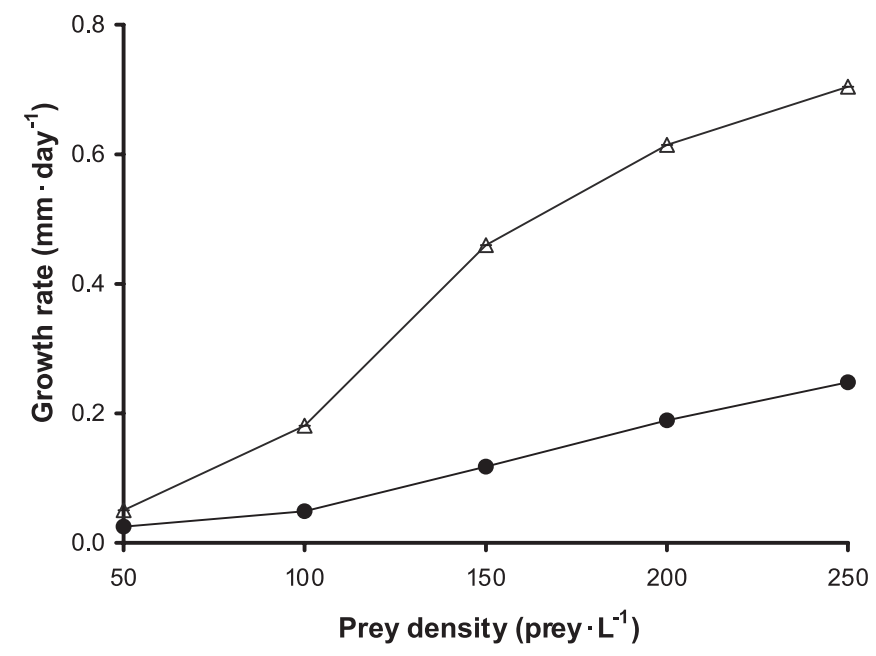

Fig. 8. Proportion of larvae that starved to death per model run $(N=1000)$ for larvae exposed to a zooplankton assemblage from nearshore Lake Michigan $(\bullet)$ or Green Bay $(\triangle)$ over a range of prey densities.

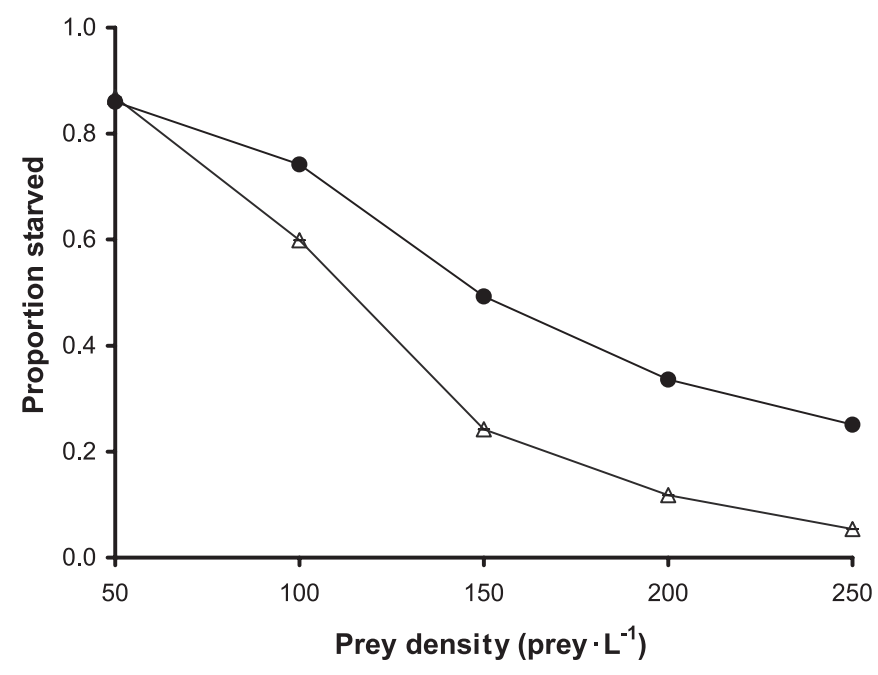

to understand both size and taxonomic selectivity for larval perch.

\section{Predicting larval diet shifts}

Our empirical approach to predicting larval diet is well suited to understanding larval responses to changing prey community composition. Traditional approaches to modeling larval foraging have used optimization rules, such as maximization of the benefit-cost ratio (Eggers 1977). This approach has two distinct disadvantages for comparing feeding selectivity between different prey assemblages. First, optimization rules are frequently based on inherent qualities of prey, and decisions regarding prey type $i$ do not directly take into account the relative abundance of all available prey types. As a result, changes in diet composition in optimality models often occur abruptly when prey density crosses a dis- 
Fig. 9. Size-frequency distribution of predicted larval survivors at 30 days after peak hatch based on model simulations $(N=3,1000$ larvae per run) at $(a, b) 100$ prey $\cdot \mathrm{L}^{-1}$ and $(c, d) 250$ prey $\cdot \mathrm{L}^{-1}$. Larvae were exposed to a prey assemblage from either $(a, c)$ nearshore Lake Michigan or $(b, d)$ Green Bay.

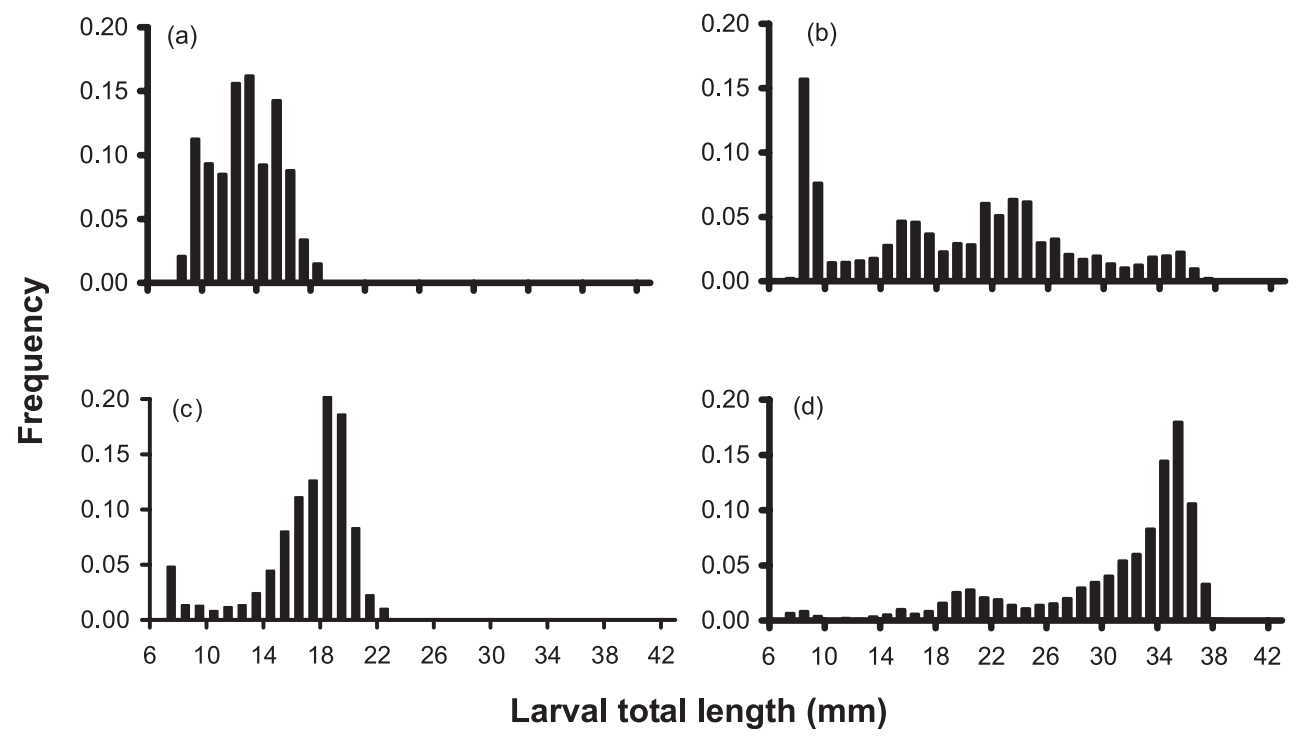

crete threshold. Such changes result in prey types being included or not included in the diet in a "knife-edge" fashion not representative of the real world (Stephens and Krebs 1986). Such optimization-based models are not well suited to predicting gradual shifts in selection, such as shifts caused by subtle changes in prey relative abundance.

A second disadvantage of optimization rules is that they require an assumption regarding what criteria would be of value to the larva to rank prey types. This criterion is usually size, as this is the most numerically and biologically tenable metric available (Eggers 1977). Prey frequently differ in other significant ways, such as behavior and morphology (Kerfoot et al. 1980), which are more difficult to quantify.

Our empirical approach to predicting prey selection for larval yellow perch allows for selection without assumptions regarding optimal criteria. That is, size is considered as a criterion for selection just as it is in an optimality model, but it is bundled with other less mathematically tenable characteristics of prey that may also be important. This approach exploits a selectivity metric (Chesson's $\alpha$ ) that describes changes in larval preference, is mathematically tenable, and is resistant to most changes in the prey assemblage. There is a minimum relative abundance greater than zero, below which selectivity data are affected, but it was extremely low in this study $(0.03 \%)$ and is only likely to be important for extremely simple prey communities (Confer and Moore 1987). By utilizing empirical data, we were able to more accurately describe how selection for a particular prey item may change both as a function of larval size and as larvae are exposed to different prey assemblages.

Two potential sources of bias exist in this empirical approach to measuring larval selectivity. First, a significant amount of variation among prey may exist within the taxonomic prey types. We have tried to define prey types in our model so that this bias is minimized. It does appear that variation among species of Daphnia may be important. The onset of positive selection for Daphnia spp. occurred rela- tively early in our selectivity trials compared with observations of yellow perch in smaller systems, likely because of differences in the size of the dominant Daphnia species between systems like Oneida Lake and Lake Michigan. Differences within the Daphnia species complex would need to be addressed to increase the generality of model results. These differences strengthen the argument that comparisons of selectivity data for larval yellow perch between systems warrant greater scrutiny.

A second potential source of bias in this analysis is differential digestion of hard- vs. soft-bodied zooplankton in larval guts (Sutela and Huusko 2000). Smaller, softer-bodied prey such as rotifers would be less likely to be present in the gut, so selection for these prey types might be underestimated. By limiting the foraging experiments to half an hour, we likely minimized the impact of this bias in comparison with analysis of field-collected larvae, for which total digestion time is unknown. Our results generally agree with recent field-based results on larval yellow perch diet in Green Bay (Bremigan et al. 2003); however, digestive bias may also be a reason why rotifers are not often cited as an important item in larval guts from field data.

Data from the literature suggest that larvae of comparable size in different systems can make very different foraging decisions. For instance, larval perch in Clear Lake, Iowa, fed primarily on copepods up to a larval size of $25 \mathrm{~mm}$ TL (Bulkley et al. 1976), but larvae of similar size in Oneida Lake, New York, showed a strong positive selection for Daphnia spp. (Mills et al. 1984). Similar studies on larval and juvenile European perch (Perca fluviatilis) have shown variance in selectivity for cladocerans vs. copepods among systems ranging from small lakes to coastal embayments, which suggests that variable selection based on prey community composition is a trait these two species share (Persson and Greenberg 1990; Mehner 2000). Such data provide evidence, as we do here, that it may be important to account for prey community composition, as well as for 
inherent preferences, when using selectivity criteria to predict diet of larval yellow perch. Moreover, the importance of community composition to a comparison of larval diet between foraging habitats will only increase as differences in community composition increase, which is more likely with increasing differences in geography and size between systems. Our empirical selectivity model is a strong tool for quantifying these differences so that we can effectively compare different yellow perch populations.

\section{Implications of diet shifts across systems}

Different foraging decisions made by larval perch in the model when exposed to nearshore Lake Michigan or Green Bay prey assemblages resulted in large differences in growth and survival. Model results suggest that larval perch in Green Bay grow faster than those in nearshore Lake Michigan at comparable prey densities. The resulting size distribution of survivors indicates that prey density affects how many individuals achieve the maximum observed growth rate, while prey community composition controls the magnitude of the maximum observed growth rate.

The bimodality in the size distributions of larval survivors predicted by the model appears to be the result of an interaction between zooplankton community composition and timing of individual hatch. Larvae that hatched into the model at times when small copepods were abundant selected for copepods at smaller larval sizes than larvae hatched when small copepods were rare relative to other available prey. This diet shift resulted in a higher initial larval growth rate, and this early growth advantage was still detectable in the bimodal size distribution of larvae 30 days after peak hatch. Post et al. (1997) observed a bimodality in the size structure of young perch cohorts in Lake St George, Ontario, in some years but not in others. They attributed this within-cohort size difference to density-dependent competition, but this splitting of a cohort into two size groups is also consistent with an early growth advantage for the part of the cohort that may be related to earlier onset of optimal feeding due to temporal differences in prey community composition.

Our model simulations did not include predation, and the character distributions of survivors would differ if predation mortality had been included. However, the higher predicted growth rate for larvae in Green Bay is also likely to result in lower vulnerability to predation. Based on differences in the size distribution of survivors, larval yellow perch growth rates in Green Bay are predicted to be more variable among individuals, resulting in a higher maximum growth rate among individuals. High growth variability among individuals means that larvae in the upper portion of the growth rate distribution are likely to reach a refuge from size-dependent predation faster; this may increase overall survival (Rice et al. 1993).

Larvae in nearshore Lake Michigan are also predicted to be less responsive to changes in prey abundance than larvae in Green Bay. Starvation rate was over $80 \%$ and mean growth rate was less than $0.1 \mathrm{~mm} \cdot \mathrm{day}^{-1}$ for larvae in both Green Bay and nearshore Lake Michigan at the lowest prey density modeled. Starvation rate decreased and growth rate increased slowly with increasing prey density for nearshore Lake Michigan in the model, and growth rates did not approach growth rates for yellow perch we observed in the field $\left(0.12-0.57 \mathrm{~mm} \cdot \mathrm{day}^{-1}\right)$ until prey densities exceeded $150 \mathrm{prey} \cdot \mathrm{L}^{-1}$. In contrast, both growth rate and starvation rate of larvae exposed to a prey assemblage from Green Bay improved more rapidly as prey density increased.

Many of the larvae predicted to starve in our model would likely be eaten before they starved to death in the natural world. The significance of our results is that in years when other forms of mortality such as predation are low in Green Bay, larval survival will likely be high, but variability in these other forms of mortality will have a less consistent effect on larval recruitment in nearshore Lake Michigan. Larval survival in nearshore Lake Michigan is primarily dependent on larvae finding high-density patches of prey to grow. Historical examinations of zooplankton density in Lake Michigan suggest this is less likely now than it was in the late 1980s when yellow perch recruitment was high (Dettmers et al. 2003). A strong initial dependence on foraging success means that in years when larval overlap with optimal prey is low, year-class strength will likely be low, but in years when this overlap is high, year-class strength could be high or low, depending on the importance of other forms of mortality. Consequently, good larval survival and a subsequent strong year class will occur less often in Lake Michigan than in Green Bay, increasing the dependence of longerterm population stability for yellow perch in Lake Michigan on extrinsic factors affecting larval survival.

These conclusions are based on prey community differences at a large scale (i.e., between systems). We did not attempt to take into account small-scale factors such as changes in foraging efficiency due to water clarity or turbulence. Furthermore, because we are comparing the zooplankton assemblages of Green Bay in 1998-1999 to nearshore Lake Michigan 2000-2001, we cannot make predictions about the year class in Green Bay being better than that in Lake Michigan in any particular year. Nonetheless, by studying the effect of community composition across multiple years and a range of zooplankton densities, it is possible to address the larger questions of whether differences in prey composition between systems are important to differences in larval survival and whether a single model of foraging behavior is sufficient to describe larval diet across a range of prey communities. Our model results suggest this is the case.

We did have to make several simplifying assumptions within the IBM framework. Most of these are part of the general IBM framework and have been well addressed previously (Letcher et al. 1996; Fulford 2003). In particular, larval foraging activity was assumed to be evenly spread across the day, and no feeding was assumed to occur at night. These assumptions are reasonable based on observations of yellow perch larval activity in tank systems (R. Fulford, unpublished data). Further, both predator and prey were assumed to be evenly distributed in space, and while this assumption may not always be true in nature, it is a reasonable simplification for comparisons of larval growth across systems.

It is important to have an understanding of how different factors affecting growth and survival of yellow perch populations may differ in importance between systems prior to making comparisons between those systems. Factors found to be important to growth and survival of larval yellow perch in smaller systems include density dependence (Post and McQueen 1988; Sanderson et al. 1999), predation (Campell 
1998; Mayer et al. 2000), interspecific competition (Roseman et al. 1996), and overwinter mortality (Post and Evans 1989). Owing to the size and depth of Lake Michigan, density-dependent effects are going to be ameliorated by larval dispersion, and long-term survey data indicate that yearclass strength is highly correlated with juvenile abundance in the fall (Clapp and Makauskas 2002), which suggests that overwinter mortality is not an important factor. The importance of predation and competitive interactions with other species such as alewife remains open. Nevertheless, our results suggest that the interaction of prey community composition in Lake Michigan with larval yellow perch selectivity patterns results in a strong relationship between prey availability and larval survival not observed in smaller systems.

Yellow perch life history seems optimized for smaller, more productive systems where survival during the pelagic phase is more consistent between years. For populations of yellow perch in systems such as Green Bay or Oneida Lake that exhibit higher larval survival (Mayer et al. 2000), population regulation is more dependent on factors regulated by perch density, such as overwinter mortality or predation during the juvenile stage (Mayer et al. 2001). In Lake Michigan, where annual recruitment appears dependent on density-independent factors such as spatial and temporal overlap with prey, recruitment patterns observed in smaller systems would have less value for predicting annual recruitment. In such cases, the individual-based modeling approach is a valuable and flexible tool for a comparative assessment of factors important to larval survival.

For larval yellow perch, the importance of diet choice constrained by limited foraging ability (e.g., first feeding) and limited availability of optimal prey items (e.g., Lake Michigan) can be both strong and important for describing patterns in annual recruitment success. Under these conditions, it is vital to describe changes in larval prey community composition in both time and space in Lake Michigan to better characterize how foraging-mediated recruitment patterns may be important to predicting population recovery.

\section{Acknowledgements}

We thank Amy Spencer, John Bridges, Brian Degan, Jeff Neuse, Rebecca Howell, Chris Heyer, Jordan Bentley, Bryce Brylawski, Juleen Dickson, and Steve Vaughan for their assistance with collecting zooplankton, conducting experiments, and processing samples. We thank Jill Weisheit of the Illinois Natural History Survey for her assistance in processing zooplankton samples from Green Bay. We thank the staff of the Wisconsin Department of Natural Resources Lake Michigan Fisheries Work Unit for the contribution of boats, personnel, and equipment. All of the laboratory experiments were conducted at the Great Lakes WATER Institute in Milwaukee, Wisconsin, and we thank the Institute staff for their guidance and support in spawning and maintaining larval yellow perch in the laboratory. This work was funded by the Great Lakes Fishery Trust, Illinois-Indiana Sea Grant, and the University of Wisconsin Sea Grant Institute under grants from the National Sea Grant College Program, National Oceanic and Atmospheric Administration, US Department of Commerce (Federal Grant No. NA86RG0047, Project
Nos. R/LR-75 and COM-PURD-643-1625-1), and matching funds from the State of Wisconsin.

\section{References}

Auer, N.A. 1982. Identification of larval fishes of the Great Lakes basin with emphasis on the Lake Michigan drainage. Great Lakes Fishery Commission, Ann Arbor, Mich., Spec. Publ. No. 82-3.

Blaxter, J.H.S. 1986. Development of sense organs and behavior in teleost larvae with special reference to feeding and predator avoidance. Trans. Am. Fish. Soc. 115: 98-114.

Bremigan, M.T., Dettmers, J.M., and Mahan, A. 2003. Zooplankton selectivity by larval yellow perch in Green Bay, Lake Michigan. J. Great Lakes Res. 29: 355-364.

Bulkley, R.V., Spykermann, V.L., and Inmon, L.E. 1976. Food of the pelagic young of walleyes and five cohabiting fish species in Clear Lake, Iowa. Trans. Am. Fish. Soc. 105(1): 77-83.

Campell, E.A. 1998. Predation by small walleyes on yellow perch: effects of prey size distribution. Trans. Am. Fish. Soc. 127: 588-597.

Chesson, J. 1983. The estimation and analysis of preference and its relationship to foraging models. Ecology, 64(5): 1297-1304.

Clapp, D., and Makauskas, D. 2002. Status of yellow perch in Lake Michigan and yellow perch task group progress report. Lake Michigan Technical Committee, Duluth, Minn.

Confer, J.L., and Lake, G.J. 1987. Influence of prey type on growth of young yellow perch (Perca flavescens). Can. J. Fish. Aquat. Sci. 44(11): 2028-2033.

Confer, J.L., and Moore, M.V. 1987. Interpreting selectivity indices calculated from field data or conditions of prey replacement. Can. J. Fish. Aquat. Sci. 44: 1529-1533.

Cowan, J.H., and Houde, E.D. 1993. The relative predation potentials of scyphomedusae, ctenophores, and planktivorous fish on ichthyoplankton in Chesapeake Bay. Mar. Ecol. Prog. Ser. 95: 55-65.

Culver, D.A., Boucherle, M.M., Bean, D.J., and Fletcher, J.W. 1985. Biomass of freshwater crustacean zooplankton from length-weight regressions. Can. J. Fish. Aquat. Sci. 42: 1380-1390.

Cushing, D.H. 1990. Plankton production and year-class strength in fish populations: an update of the match/mismatch hypothesis. Adv. Mar. Biol. 26: 249-293.

Dettmers, J.M., Raffenberg, M.J., and Weis, A.K. 2003. Exploring zooplankton changes in southern Lake Michigan: implications for yellow perch recruitment. J. Great Lakes Res. 29(2): 355-364.

DeVries, D.R., Bremigan, M.T., and Stein, R.A. 1998. Prey selection by larval fishes as influenced by available zooplankton and gape limitation. Trans. Am. Fish. Soc. 127(6): 1040-1050.

Dumont, H.J., Van de Velde, I., and Dumont, S. 1975. The dry weight estimate of biomass in a selection of cladocera, copepoda and rotifera from the plankton, periphyton, and benthos of continental waters. Oecologia, 19: 75-97.

Eggers, D.M. 1977. The nature of prey selection by planktivorous fish. Ecology, 58: 46-59.

Fuiman, L.A., Smith, M.E., and Malley, V.N. 1999. Ontogeny of routine swimming speed and startle responses in red drum, with a comparison of responses to acoustic and visual stimuli. J. Fish. Biol. 55(Suppl. A): 215-226.

Fulford, R.S. 2003. Food-web interactions of larval yellow perch, Perca flavescens, in Lake Michigan: implications for recruitment. Ph.D. dissertation, North Carolina State University, Raleigh, N.C.

Graeb, B.D.S., Dettmers, J.M., Wahl, D.H., and Caceres, C.E. 2004. Experimental evaluation of growth, survival, prey selection, and 
foraging behavior of larval yellow perch. Trans. Am. Fish. Soc. 133: $504-514$.

Hansen, M.J., and Wahl, D.H. 1981. Selection of small Daphnia pulex by yellow perch fry in Oneida Lake, New York. Trans. Am. Fish. Soc. 110: 64-71.

Hanson, P.C. 1997. Fish bioenergetics. University of Wisconsin Sea Grant Institute, Madison, Wis.

Houde, E.D. 1969. Sustained swimming ability of larvae of walleye (Stizostedium vitreum) and yellow perch (Perca flavescens). J. Fish. Res. Board Can. 26: 1647-1659.

Jenkins, R.E., and N.M. Burkhead. 1994. Fishes of Virginia. American Fisheries Society, Bethesda, Md.

Kerfoot, W.C., Kellogg, D.L., Jr., and Strickler, J.R. 1980. Visual observations of live zooplankters: evasion, escape, and chemical defenses. In Evolution and ecology of zooplankton communities. Edited by W.C. Kerfoot. University Press of New England, Hanover, N.H. pp 10-27.

Letcher, B., Rice, J.A., Crowder, L.B., and Rose, K.A. 1996. Variability in survival of larval fish: disentangling components with a generalized individual-based model. Can. J. Fish. Aquat. Sci. 53: 787-801.

Lockwood, J.R. 1998. On the statistical analysis of multiple-choice feeding preference experiments. Oecologia, 116(4): 475-481.

Madenjian, C.P., Fahnenstiel, G.L., Johengen, T.H., Nalepa, T.F., Vanderploeg, H.A., Fleischer, G.W., Schneeberger, P.J., Benjamin, D.M., Smith, E.B., Bence, J.R., Rutherford, E.S., Lavis, D.S., Robertson, D.M., Jude, D.J., and Ebener, M.P. 2002. Dynamics of the Lake Michigan food web, 1970-2000. Can. J. Fish. Aquat. Sci. 59: 736-753.

Mayer, C.M., VanDeValk, A.J., Forney, J.L., Rudstam, L.G., and Mills, E.L. 2000. Response of yellow perch (Perca flavescens) in Oneida Lake, New York, to the establishment of zebra mussels (Dreissena polymorpha). Can. J. Fish. Aquat. Sci. 57: 742-754.

Mayer, C.M., Rudstam, L.G., Mills, E.L., Cardiff, S.G., and Bloom, C.A. 2001. Zebra mussels (Dreissena polymorpha), habitat alteration, and yellow perch (Perca flavescens) foraging: system-wide effects and behavioural mechanisms. Can. J. Fish. Aquat. Sci. 58(12): 2459-2467.

Mehner, T. 2000. Influence of spring warming on the predation rate of underyearling fish on Daphnia - a deterministic simulation approach. Freshw. Biol. 45(2): 253-263.

Mills, E.L., and Forney, J.L. 1981. Energetics, food consumption, and growth of young yellow perch in Oneida Lake, New York. Trans. Am. Fish. Soc. 110: 479-488.

Mills, E.L., Confer, J.L., and Ready, R.C. 1984. Prey selection by young yellow perch: the influence of capture success, visual acuity, and prey choice. Trans. Am. Fish. Soc. 113: 579-587.

Neter, J., Wasserman, W., and Kutner, M.H. 1990. Applied linear statistical models. 3rd ed. Irwin, Boston, Mass.

Persson, L., and Greenberg, L.A. 1990. Optimal foraging and habitat shift in perch (Perca fluviatilis) in a resource gradient. Ecology, 71(5): 1699-1713.
Post, J.R., and Evans, D.O. 1989. Size-dependent overwinter mortality of young-of-the-year yellow perch (Perca flavescens): laboratory, in situ enclosure, and field experiments. Can. J. Fish. Aquat. Sci. 46: 1958-1968.

Post, J.R., and McQueen, D.J. 1988. Ontogenetic changes in the distribution of larval and juvenile yellow perch (Perca flavescens): a response to prey or predators? Can. J. Fish. Aquat. Sci. 45(10): $1820-1826$.

Post, J.R., Johannes, M.R.S., and McQueen, D.J. 1997. Evidence of density-dependent cohort splitting in age-0 yellow perch (Perca flavescens): potential behavioral mechanisms and population-level consequences. Can. J. Fish. Aquat. Sci. 54: 867-875.

Rice, J.A., Miller, T.J., Rose, K.A., Crowder, L.B., Marschall, E.A., Trebitz, A.S., and DeAngelis, D.L. 1993. Growth rate variation and larval survival: inferences from an individual-based size dependent predation model. Can. J. Fish. Aquat. Sci. 50: 133-142.

Roseman, E.F., Mills, E.L., Forney, J.L., and Rudstam, L.G. 1996. Evaluation of competition between age-0 yellow perch (Perca flavescens) and gizzard shad (Dorosoma cepedianum) in Oneida Lake, New York. Can. J. Fish. Aquat. Sci. 53(4): 865-874.

Sanderson, B.L., Hrabik, T.R., Magnuson, J.J., and Post, D.M. 1999. Cyclic dynamics of a yellow perch (Perca flavescens) population in an oligotrophic lake: evidence for the role of interspecific interactions. Can. J. Fish. Aquat. Sci. 56: 1534-1542.

SAS Institute Inc. 2002. Statistical analysis system. Version 8.2. SAS Institute Inc., Cary, N.C.

Schael, D.M., Rudstam, L.G., and Post, J.R. 1991. Gape limitation and prey selection in larval yellow perch (Perca flavescens), freshwater drum (Aplodinotus grunniens), and black crappie (Pomoxis nigromaculatus). Can. J. Fish. Aquat. Sci. 48(10): 1919-1925.

Sharp, G.D. 1987. Averaging the way to inadequate information in a varying world. Am. Inst. Fish. Res. Biol. Briefs, 16: 3-4.

Shroyer, S.M., and McComish, T.S. 2000. Relationship between alewife abundance and yellow perch recruitment in southern Lake Michigan. N. Am. J. Fish. Manag. 20: 220-225.

Siefert, R.E. 1972. First food of larval yellow perch, white sucker, bluegill, emerald shiner, and rainbow smelt. Trans. Am. Fish. Soc. 101(2): 219-225.

Stephens, D.W., and Krebs, J.R. 1986. Foraging theory. Princeton University Press, Princeton, N.J.

Sutela, T., and Huusko, A. 2000. Varying resistance of zooplankton prey to digestion: implications for quantifying larval fish diets. Trans. Am. Fish. Soc. 129: 545-551.

Wahl, C.M., Mills, E.L., McFarland, W.N., and DeGisi, J.S. 1993. Ontogenetic changes in prey selection and visual acuity of the yellow perch, Perca flavescens. Can. J. Fish. Aquat. Sci. 50: 743-749.

Webb, P.W., and Weihs, D. 1986. Functional locomotor morphology of early life history stages of fishes. Trans. Am. Fish. Soc. 115: $115-127$. 
Copyright of Canadian Journal of Fisheries \& Aquatic Sciences is the property of NRC Research Press and its content may not be copied or emailed to multiple sites or posted to a listserv without the copyright holder's express written permission. However, users may print, download, or email articles for individual use. 